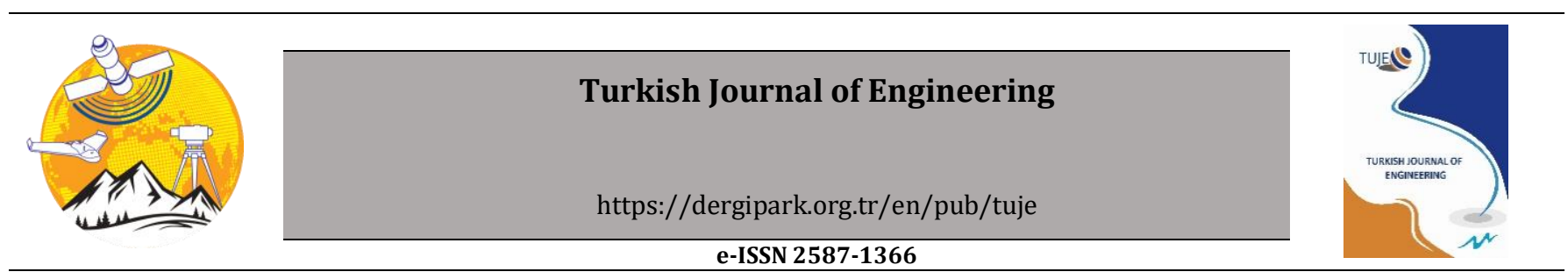

\title{
Numerical simulation and experimental investigation: Metal spinning process of stepped thin-walled cylindrical workpiece
}

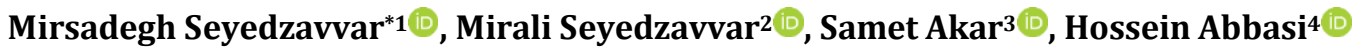 \\ ${ }_{1}^{1}$ Adana Alparslan Turkeș Science and Technology University, Faculty of Engineering, Department of Mechanical Engineering, Adana, \\ Turkey \\ 2University of Tabriz, Faculty of Mechanical Engineering, Department of Manufacturing, Tabriz, Iran \\ ${ }^{3}$ Çankaya University, Engineering Faculty, Department of Mechanical Engineering, Ankara, Turkey \\ ${ }_{4}^{4}$ Technical and Vocational University, Tabriz Branch No.1, Department of Mechanical Engineering, Tabriz, Iran
}

\author{
Keywords \\ Sheet metal \\ Spinning process \\ Feed rate \\ Mandrel rotational speed \\ Stress and strain \\ Wrinkling.
}

\begin{abstract}
Many equipment and devices utilized in the aerospace industry are formed as symmetric parts through high plastic deformation of high strength sheet metal alloys with low thickness. Considering the inherent advantages of the spinning process of simple tooling and concentrated deformation loading, this process can be considered as one of the main options in producing these thin-sectioned lightweight parts. In this study, a Finite Element (FE) model has been developed to simulate the formation of a stepped thin-walled cylindrical workpiece of AISI 316 stainless steel alloy by spinning process. The FE simulation results were employed to investigate the effects of process parameters, including feed rate of the roller and rotational velocity of the mandrel on the distribution of stress and strain in the sheet metal, wrinkling failure, and thinning of the sheet metal during deformation. Experiments were carried out using selective input parameters based on the results of FE simulations. The comparison between FE simulations and experiments revealed that the developed model could predict the thinning of the sheet metals with over $93 \%$ accuracy. Additionally, a good agreement between the experimentally deformed sheet configurations with those resulting from finite element simulations has been observed.
\end{abstract}

\section{INTRODUCTION}

The spinning process is an incremental metal forming process in which the raw material, in the form of sheet metal, is formed by a roller-type tool on a preformed die called mandrel. The mandrel and the sheet metal which is supported by a holder mounted at the end of the tailstock are rotated. A concentrated force is applied on the sheet metal by the roller, which acts as a lever tool and causes the material to flow along with the mandrel's surface profile (Kalpakjian and Schmid, 2006).

Several studies have been conducted on the spinning process of different symmetrical shapes to determine the distribution of stress and strain in the workpiece and to explore the governing mechanisms in the deformation process. Moria et al. (2009) performed a hot spinning process of cast aluminum alloy to remove the casting imperfections and produce parts with uniform wall thickness. Li et al. (2014) simulated the thickness variations and deformation of sheet metal by the roller's movement in a die-less spinning process. Wong et al. (2008) studied the effects of the roller dimensions and reduction of the cross-section on the material flow in the thin-walled cup spinning process. The results showed that the roller edge radius determines the degree of plastic deformation along the wall length of the cup. Mori and Nonanka (2005) developed a finite element (FE) model to simulate the shear spinning process of an aluminum cone flange. They reported that the built-up edge of the material in front of the roller is promoted by an increase in the edge radius of the roller and the thickness reduction of the material during the deformation process. Jahazi and Ebrahimi (2000) studied the role of shear spinning process parameters on the spring back and tearing of the sheet metal in the deformation process. Wang et al. (2010) investigated the wrinkling failure of cylindrical cups in the spinning process. They reported that there is a threshold for the feed rate of the roller over which the wrinkling of the material occurs during the deformation
Seyedzavvar M, Seyedzavvar M, Oliaei S N B \& Abbasi H (2022). Numerical simulation and experimental investigation: Metal spinning process of stepped thin-walled cylindrical workpiece. Turkish Journal of Engineering, 6(1), 67-80 
process. Marghmaleki et al. (2011) employed FE method to evaluate the effects of heat generated during the plastic deformation of materials and the friction between the sheet metal and the tool on the distribution of stress and strain in the workpiece and the deformation energy of the spinning. Cheung et al. (2013) simulated the plastic flow of materials during the forming process using FE method. They employed the results to predict the equivalent strain and thickness of tubular cups in the spinning process. The authors predicted the probability of cracking and the location of a crack in the cup wall during the thickness reduction step and the height of the final part with $80 \%$ accuracy as compared with the experiments. Wang et al. (2017) studied the role of the spinning process in reducing the size of crystalline grains of aluminum-alloy plates. They showed that the increase of the equivalent strain during the spinning process causes a further reduction of the size of crystalline grains of the workpiece. Sangkharat and Dechjarern (2017) conducted FE modeling of the spinning process of SPCC sheet metals to investigate the thinning and wrinkling failure of the blank during the deformation process. Ahmed et al. (2015) investigated the wrinkling failure and wall thickness distribution of a cup specimen in a deep spinning process under different roller feed rates and nose radii. They considered a constant clearance between the roller and the mandrel. The results showed that the spinning ratio, defined as the blank to mandrel diameter ratio, and the roller feed rate could be doubled without failure of the sample by annealing the aluminum sheets before the spinning process.

Additionally, attempts to produce axisymmetric and asymmetric components by the spinning process without a mandrel have been reported in some papers. Jia et al. (2015) studied the effects of process parameters, including roller feed rate, nose radius, roller path, and half-core angle, on the surface quality of specimen in the square-section die-less spinning process. They also modeled Al 6061 blank as a deformable 3D solid. The other components of the spinning process were modeled as discrete-rigid in Abaqus/Explicit environment to achieve the strain fields in the workpiece during deformation. It was reported that a smaller roller nose radius causes higher axial plastic strains, deeper indentations, and lower surface quality of the specimen. Sugita and Arai (2015) performed multi-pass spinning to produce a circular cup and a rectangular box without using a mandrel. They evaluated the effects of tool trajectory and inclination angle on the wall thickness and wrinkling of the spun parts. They reported higher spinning ratio for axisymmetric components than asymmetric forms. Russo et al. (2020) investigated the formation of asymmetric parts of 1050-H14 aluminum alloy in a multi-pass mandrel-free spinning process by controlling the trajectory of two rollers, namely the blending and working rollers. Their study aimed to develop an algorithm of tool path generation that could be applied to all target geometries, while avoiding tearing and minimizing thinning and shape errors of the spun samples.

Furthermore, the spinning process has been employed in the flow forming of tubes. In this regard, Murata et al. (2005) showed that with increasing pipe diameter reduction, the resistance of the workpiece to plastic deformation and the thickness of the tube wall increases, leading to higher rigidity of the deformed part and reduction of spring back of the material. Xia et al. (2012) conducted experiments and FE modeling to study the stress and strain distribution, thickness reduction, straightness, ellipticity, and elongation of the workpiece in the fabrication process of an automobile exhaust pipe muffler by a non-symmetric spinning method. They reported that the multi-pass spinning process causes longitudinal tensile strain and circumferential compressive strain at the spun workpiece. Davidson et al. (2008) studied the production of seamless thin-walled tubes of AA6061 annealed tubes using a spinning flow forming process. They reported that the diametric expansion of the tube can be avoided at a roller feed rate in the range of $0.83 \sim 1.67 \mathrm{~mm} / \mathrm{s}$. Parsa et al. (2009) simulated the deformation of tube stirred by forward material flow in the spinning process using explicit finite element method. Molladavoudi and Djavanroodi (2011) studied the role of thinning of the tubes as a result of the spinning process on the mechanical properties, surface finish, hardness, dimensional accuracy, and crystalline structure of the formed parts. Huang et al. (2011) used the FE method to study the effects of coefficient of friction, feed rate, and edge radius of the roller on the deformability of JIS G3141 steel in the throat spinning process. The results showed that the ellipticity of the cross-section and twisting of the tube increase with increasing the roller feed rate. Bi et al. (2012) simulated the automobile wheel forming in the spinning process using 3D Deform FE software to determine the required length of raw material and optimum parameter settings of the spinning process. Becker and Tekaya (2015) used a combination of spinning and tube bending processes to make exhaust pipes of automobiles. Zhan et al. (2018) investigated the formation of flaring defect at the opening end of the tube in the forward tube spinning process and reported that a small feed rate and reduction per path reduced maximum flaring at the expense of productivity.

Reviews of the previous research revealed that although the spinning process has a high potential in manufacturing complex shapes in response to the increasing demand by global manufacturing industries, especially aerospace engineering, it is complicated in terms of the influence of process parameters on the deformation characteristics. Among various spinning process parameters such as nose radius, attack angle, the feed rate of the roller, and the rotational speed of mandrel, the latter two variables have been shown to have the most significant influence on the spinnability of material (Wong et al. 2003). In this paper, the formation of a stepped thin-walled cylinder of AISI 316 stainless steel by the spinning process is presented. High hardness, high corrosion resistance, and strength against deformation are among the characteristics of this steel that promote its wide applications in the aerospace industry (AMS 5528). In contrast, these properties make it difficult to plastically deform thin sheet metals of this material by forming methods such as deep drawing. However, the spinning process has the advantage of creating a local plastic deformation zone at the sheet 
metal at its contact area with the roller that reduces the power requirements and the size of equipment and tools of the metal forming process.

To the best of our knowledge, the application of the spinning process in the production of stepped thinwalled cylindrical parts, especially for the ones made of this research, a FE model of the metal spinning process of a typical stepped cylindrical part has been developed using Abaqus/Explicit software to investigate the role of process parameters on the stress and strain distribution in the workpiece and their correlations with the wrinkling failure and nonuniformity in thinning of the wall of the workpiece. The experiments were carried out using selective input parameters based on the results of FE simulations. Similarities between the configuration of the samples deformed experimentally with those simulated in the FE model, as well as comparisons of the thickness of the deformed sheet metals in experiments with the results obtained by FE simulations were used to verify the accuracy of the developed FE model.

\section{FINITE ELEMENT MODEL}

In this section, the dimensions and specifications of the workpiece and the main components involved in the spinning process are introduced. In the case of problems where complex reactions exist between the interacting surfaces, the explicit integration method is more effective than implicit integration (Feifei et al. 2003). In this regard, and considering the dynamic nature of the interaction between the surfaces and the degree of plastic deformation in the spinning process, the Abaqus/Explicit has been used to model the forming process of the stepped thin-walled cylindrical workpiece

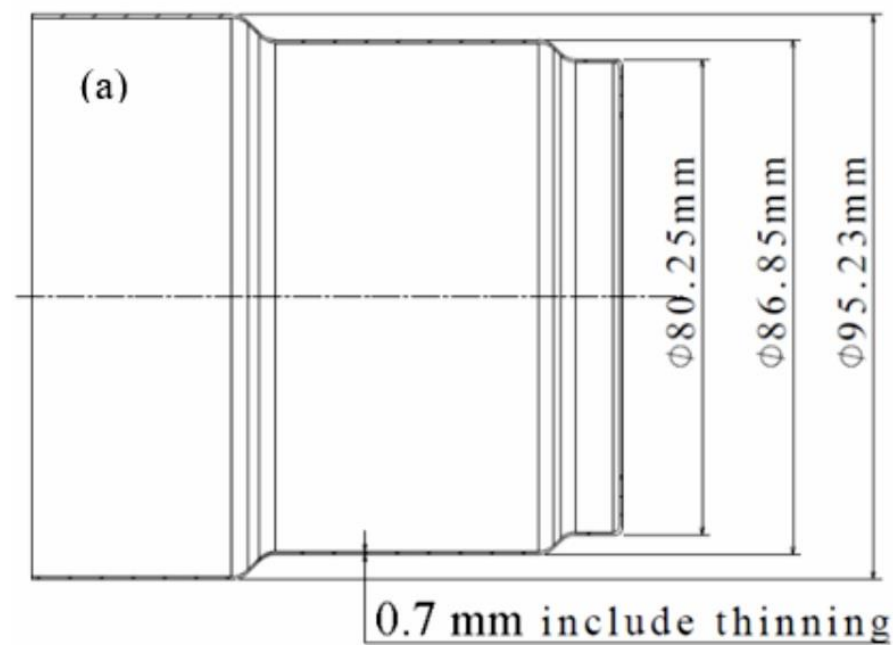
high strength stainless steels, has not been reported. In

(Huang et al. 2011). During the simulations it was assumed that the sheet metal material was homogeneous, the friction was constant throughout the deformation, and the heat generation effects during the deformation were negligible.

\subsection{Definition of Parts Involved in FE Simulation}

The model of the stepped thin-walled cylindrical workpiece is represented in Fig. 1. Accordingly, the thickness of this workpiece is $0.7 \mathrm{~mm}$ with the two steps along the longitudinal axis. Also, the assembly of different parts involved in the spinning process is shown in Fig. 2. The mandrel was designed based on the sectional profile of the workpiece (Kalpakjian and Schmid 2006; Li et al. 2014). The sheet metal was held at the center of the mandrel by a compressive force applied from the sheet metal support. The roller was designed using the dimensions provided by Moria et al. (2009) and Li et al. (2014). Accordingly, the roller diameter, edge radius, and attack angle were equal to $146 \mathrm{~mm}, 4 \mathrm{~mm}$, and $30^{\circ}$, respectively. To prevent numerical errors due to the volumetric variation of the workpiece in the dynamicexplicit analysis caused by the rotation of the deformable part, the rotation of the roller was defined around the mandrel axis with a velocity equal to that of the mandrel (Huang et al. 2011). Given the limitation of rotating a rigid body around an eccentric axis, a second part is defined as the roller support. The definition of the interaction between the roller support and the roller provides the roller rotation around the axis of the workpiece. It simultaneously stirs its movement along the axis of the mandrel, which is described in the following section.

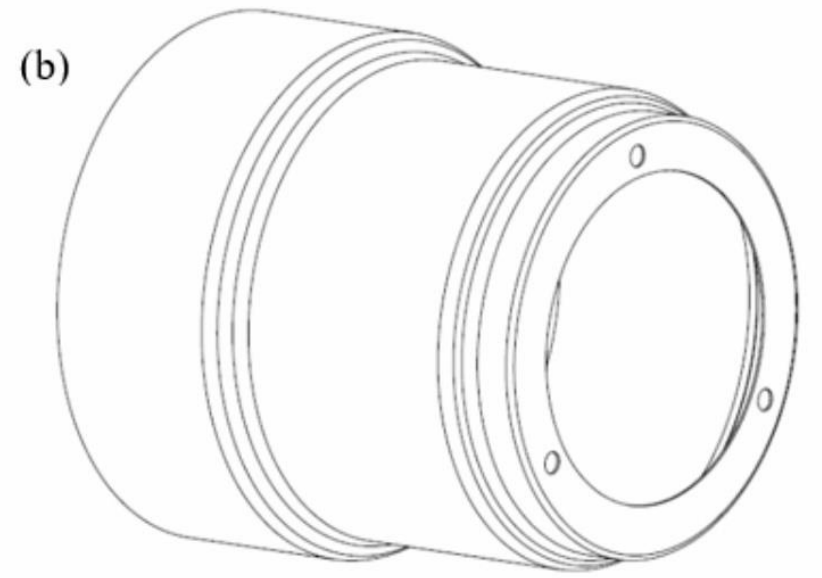

Figure 1. Design of the stepped thin-walled cylindrical workpiece; a) cutting view along the longitudinal axis and b) isometric view

The mandrel, the sheet metal support, and the roller were introduced as discrete rigid parts in the Abaqus/CAE environment, while the blanks and the roller support were defined as deformable parts. The characteristics of rigid parts, including weight and mass moment of inertia, were introduced by defining a reference point to each part and assigning these properties to these points. Physical and mechanical properties of the sheet metal and roller support were defined based on the physical and mechanical properties of AISI 316 stainless steel (table (1)). The chemical composition of this material included; C $0.03 \%$, Si $0.46 \%$, Mn 1.78\%, P 0.028\%, S 0.027\%, Ni 10.1\%, Cr 16.8\%, Mo $1.99 \%$ and $\mathrm{N} 0.07 \%$. The true stress-strain data of as annealed samples of this material was acquired by standard tensile tests using Amsler tensile test machine 
and split Hopkinson pressure bar (SHPB) apparatus under different deformation rates at room temperature (Sreenivasan and Rayb (2001). The acquired data are represented in Fig. 3. The strain-rate dependent plastic properties of the samples were introduced in tabulated form to the Abaqus/CAE environment.

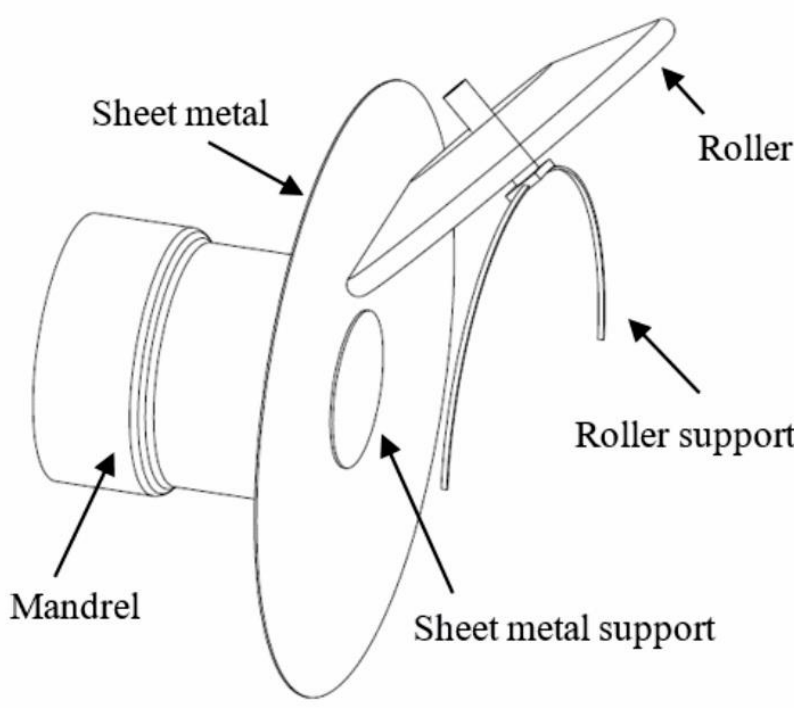

Figure 2. Isometric view of the assembly of different components in the spinning simulation of the stepped thin-walled cylindrical workpiece

Table 1. Physical properties of AISI 316 stainless steel (AMS 5528).

\begin{tabular}{ll}
\hline Property & Quantity \\
\hline Density $\left(\mathrm{kg} / \mathrm{dm}^{3}\right)$ & 7.87 \\
Poisson's ratio & 0.27 \\
Modulus of elasticity $(\mathrm{GPa})$ & 190 \\
Thermal conductivity $(\mathrm{W} / \mathrm{m} . \mathrm{K})$ & 15 \\
Thermal expansion $\left(\mu \mathrm{m} / \mathrm{m}^{\circ} \mathrm{C}\right)$ & 16 \\
\hline
\end{tabular}

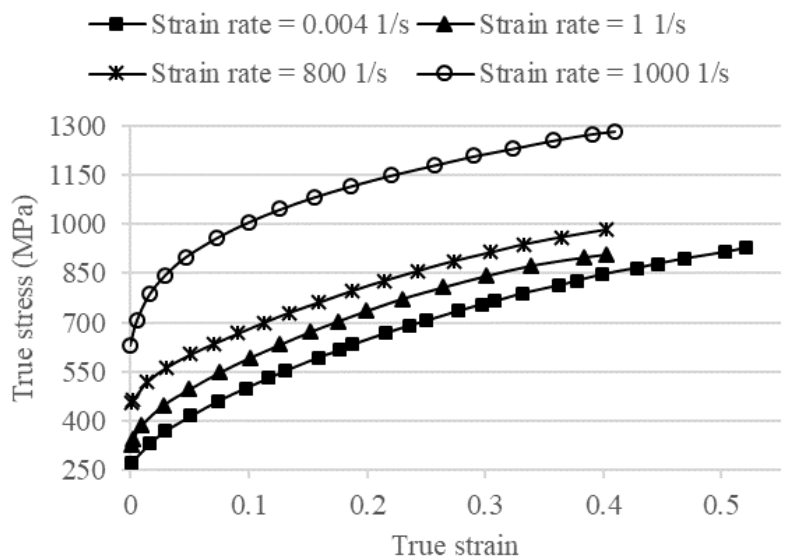

Figure 3. Stress-strain response of as annealed AISI 316 steel under various strain rates

\subsection{Definition of Simulation Steps, Interactions, Constraints, and Loadings}

As shown in Fig. 4, the roller movement paths were defined according to the surface profile of the mandrel, represented in the same graph, while maintaining the distance between the roller and the mandrel equal to the thickness of the sheet metal. Taking the nature of the interaction between different parts in the spinning process into account, dynamic explicit steps were defined, and the duration of each step was assigned by considering the feed rate of the roller. A mass scaling of $10^{3}$ was used in the simulations. In each of the horizontal paths, the roller and the roller support moved simultaneously, while in the ascending paths, the roller continued to move along the longitudinal axis of the mandrel, while the roller support rotated with the defined speed without displacement. To reduce the simulation time, the progress of the roller was continued up to the middle of the path (3).
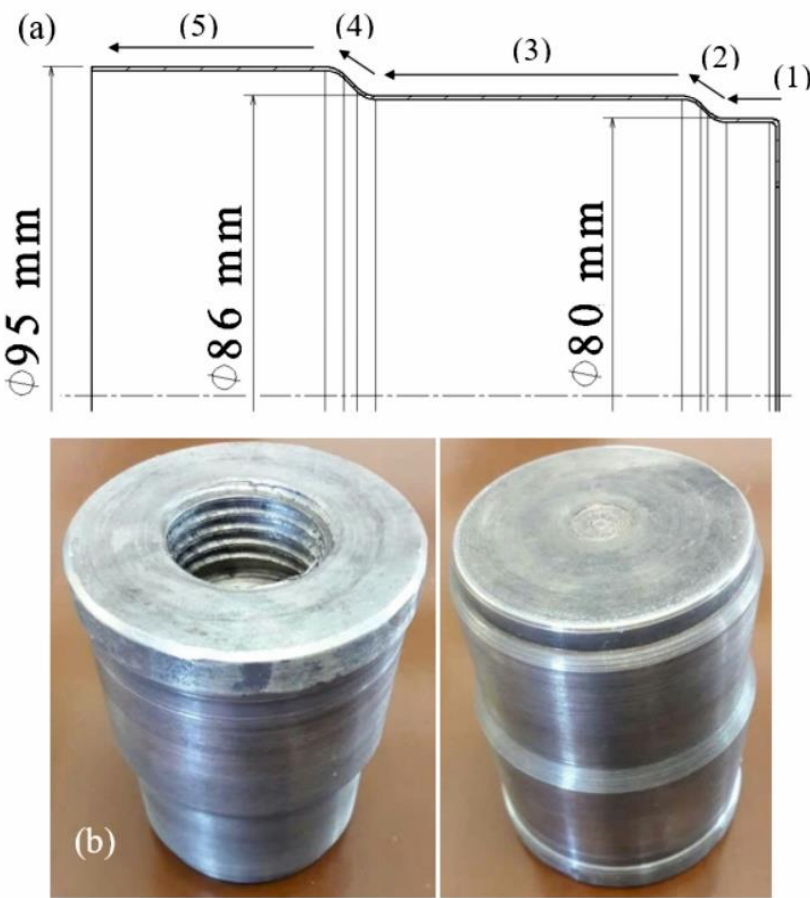

Figure 4. Roller path definition for the spinning process; a) paths defined along with the mandrel surface profile and $b$ ) mandrel used for the spinning process

Three different types of interactions have been defined between the interacting surfaces in the spinning process. Considering the limitation that it is not possible to transfer motion between two rigid bodies in Abaqus/CAE, the roller support was imported in the Abaqus environment as a deformable body, and then a rigid coupling was assigned to it. Therefore, the interaction property between the surfaces of the roller support and the roller was defined as hard contact. This feature allowed for the separation of surfaces after the engagement. Furthermore, the interaction between the surfaces of the sheet metal and the mandrel, as well as between the surfaces of the sheet metal and the sheet metal support was defined as surface-to-surface contact with tangential behavior having the coefficient of friction of 0.2 (Huang et al. 2011). Additionally, the interaction between the surfaces of the sheet metal and the roller was defined as surface-to-surface contact with tangential behavior having the coefficient of friction of 0.1 and normal behavior of hard contact (Wong et al. 2008).

Given the fact that the rotation of the mandrel and consequently the rotation of the sheet metal were simulated by the rotation of the roller around the mandrel axis, all degrees of freedom of the mandrel was 
constrained. Additionally, all degrees of freedom of the sheet metal support were restricted except that of along the longitudinal axis of the mandrel. A compressive pressure of $50 \mathrm{MPa}$ was applied to the sheet metal support to simulate the force applied on the sheet metal from the tailstock to hold it concentric with the mandrel during the spinning process. On the other hand, the roller movement along the axis of the mandrel was generated by assigning a linear/rotational velocity constraint to its reference point and applying the desired velocity along the longitudinal axis of the mandrel, while other degrees of freedom were not restricted. Furthermore, to create the rotational motion of the roller, a linear/rotational velocity was applied to the reference point of the roller support and a specified velocity was applied about the mandrel axis. The levels of process parameters are represented in table 2 .

Table 2. Parameters of the metal spinning process of a stepped thin-walled cylinder

\begin{tabular}{ll} 
Mandrel rotational speed, $\omega(\mathrm{rad} / \mathrm{s})$ & $20,40,60$ \\
Roller feed rate, $\mathrm{f}(\mathrm{mm} / \mathrm{s})$ & $2,5,8$ \\
Roller attack angle $(\mathrm{deg})$ & $30^{0}$ \\
Nose radius of roller $(\mathrm{mm})$ & 4 \\
\hline
\end{tabular}

\subsection{Discretization, Definition of Elements, and Meshing}

The elements defined for rigid bodies were 3-node 3D rigid triangular facet (R3D3) elements. The edges of the roller and the mandrel were discretized by smaller dimensions than the average elements of the rigid bodies to improve their interaction with sheet metal. The sheet metal was discretized uniformly with an element size of $1.2 \mathrm{~mm}$ on the surface and with three elements along the thickness. The choice of this size was based on the convergence of the results of FE analysis. Solid elements are more accurate in contact modeling than shell elements as they take two-side contact into account and reflect the stress/strain more precisely. Therefore, the type of elements selected for the sheet metal was a general-purpose 8-node linear brick element (C3D8R) with reduced integration to overcome the locking phenomena associated with C3D8 elements. Hourglass control was activated for this element to eliminate incorrect solutions with artificially large displacements in response to zero energy modes (DAP).

\section{RESULTS and DISCUSSION}

In this section, results of the FE analyses and experiments of the forming process of a stepped thinwalled cylindrical workpiece of AISI 316 stainless steel are presented and the effects of process parameters in the deformation process are discussed. The experiments were carried out on a CJ-SW1200 CNC spinning machine using selective input parameters based on the results of FE analysis. Comparisons between the configurations and thicknesses of the samples in FE simulations and experiments were used to verify the accuracy of the developed FE model.

\subsection{Verification of the Accuracy of the FE Model}

The first step to evaluate the accuracy of the developed FE model was to ensure that the solution was quasi-static and therefore the initial effect due to mass scaling was well-controlled (Huang et al. 2011). In this regard, the ratio of kinetic energy (ALLKE) to the internal energy (ALLIE) of deformation of the sheet metal should stay below $10 \%$ during the deformation process. Therefore, the history outputs of KLLE and ILLE were defined for a set assigned to the blank during the FE simulations, and the results of the ALLKE/ALLIE ratio were evaluated for all the simulations at various process parameters. The typical result under the process parameters of the mandrel speed of $40 \mathrm{rad} / \mathrm{s}$ and the roller feed rate of $5 \mathrm{~mm} / \mathrm{s}$ is represented in Fig. 5. As shown in this figure, except for the initial stage of the simulation that there was a small engagement of the roller with the blank and little plastic deformation, the ratio of ALLKE/ALLIE stayed below $10 \%$. Therefore, the initial effects have not affected the simulation process due to the mass scaling of $10^{3}$.

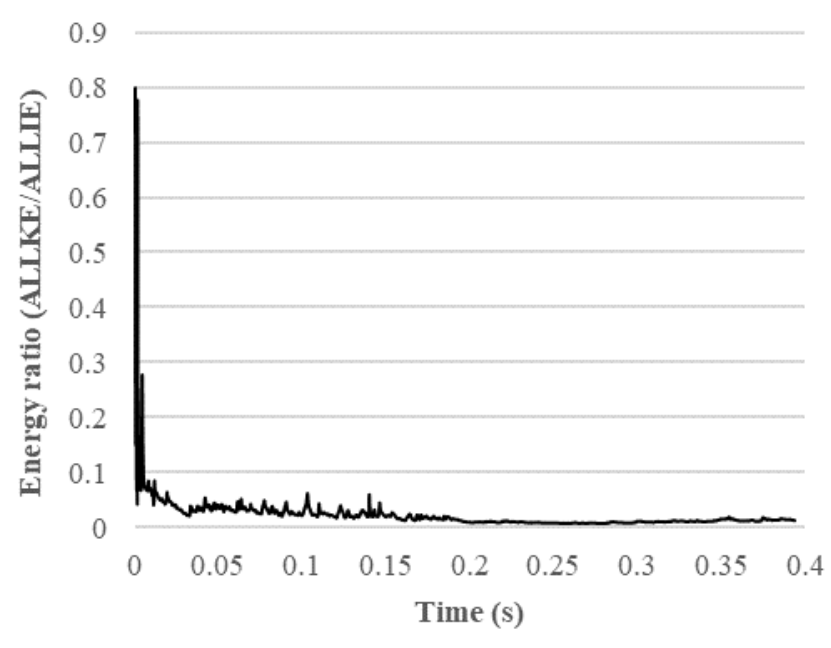

Figure 5. ALLKE/ALLIE ratio versus time in FE simulation of spinning process at $\mathrm{f}=5 \mathrm{~mm} / \mathrm{s}$ and $\omega=40$ $\mathrm{rad} / \mathrm{s}$

Additionally, the error between the wall thickness of the workpiece deformed in FE simulations with that of shaped experimentally was used to evaluate the accuracy of the FE model. The results of these measurements for the spun part under typical process parameters of the roller feed rate of $5 \mathrm{~mm} / \mathrm{s}$ and mandrel rotational speed of $60 \mathrm{rad} / \mathrm{s}$ is represented in Fig. 6. To do the experimental measurements, the workpiece was cut along the longitudinal axis after the spinning process using a wire cut machine and the thickness of the section was measured by a micrometer. The thickness of the deformed sheet metal in FE simulation was calculated based on the distributed strain in the radial direction of the sample and application of Eq. 1 (Huang et al. 2011).

$$
\varepsilon_{t}=\ln \left(t / t_{0}\right)
$$

where $\varepsilon_{\mathrm{t}}$ is the radial strain at any distance from the head of the workpiece, $t$ and $t_{0}$ are the instantaneous and initial 
thickness of the specimen, respectively. Regarding the variation of the radial strain along different orientations of each cross-section, an average of $\varepsilon_{t}$ were calculated using the distribution of radial strain along different longitudinal paths of the specimen. Based on the comparison between the results acquired by experiments and FE simulations, the developed FE model was able to predict the thickness of the deformed sheet metal with a maximum error of less than $6.2 \%$ and an average error of $3.4 \%$. Therefore, the thickness of the spun parts in experiments at different cross-sections was found to have no significant difference from that acquired in FE simulations.
Furthermore, the configurations of the samples in the FE model were compared with that of deformed experimentally under selective process parameters to evaluate the accuracy of the FE model in the prediction of the shape of the blank after the spinning process. Figure 7 shows the results under spinning parameters of $f=2$ $\mathrm{mm} / \mathrm{s}$ and $\omega=60 \mathrm{rad} / \mathrm{s}$. As shown in this figure, there is a good agreement between the FE and experimental results which confirms the fact that the developed FE model for simulation of thin-walled cylindrical parts can predict the features of experimentally deformed parts with high accuracy.

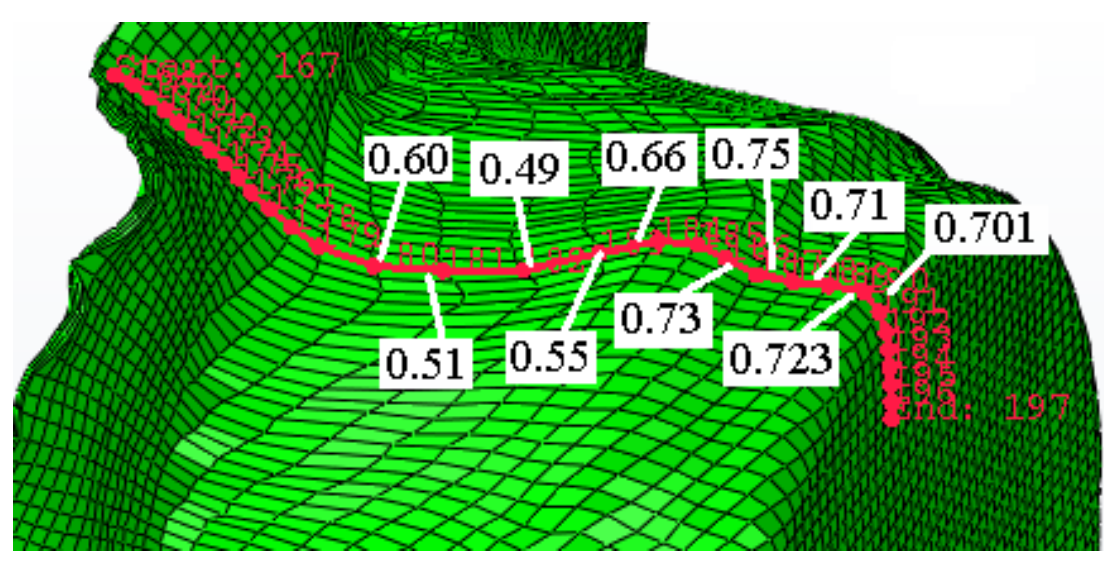

(a)

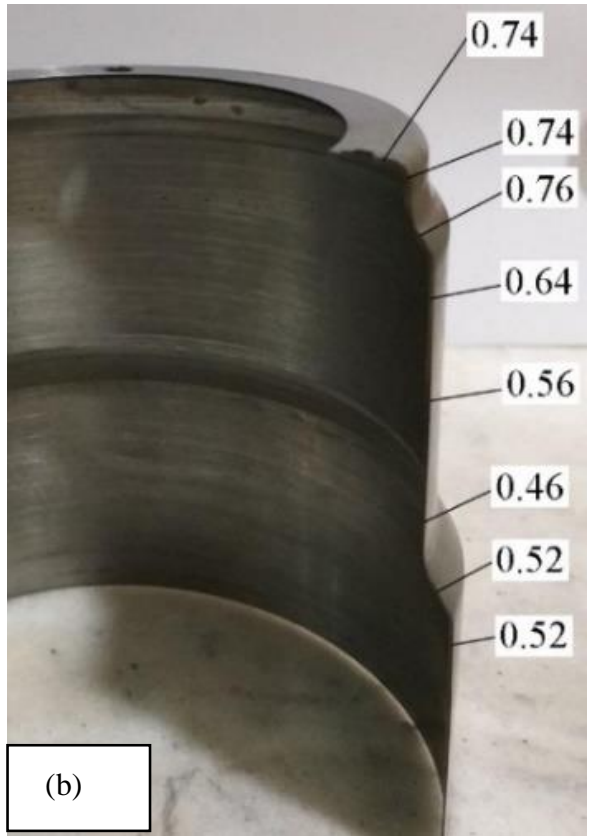

Figure 6. Variation of the thickness of specimen spun under feed rate of $5 \mathrm{~mm} / \mathrm{s}$ and a spindle speed of $40 \mathrm{rad} / \mathrm{s}$; a) $\mathrm{FE}$ simulation and b) experiment.
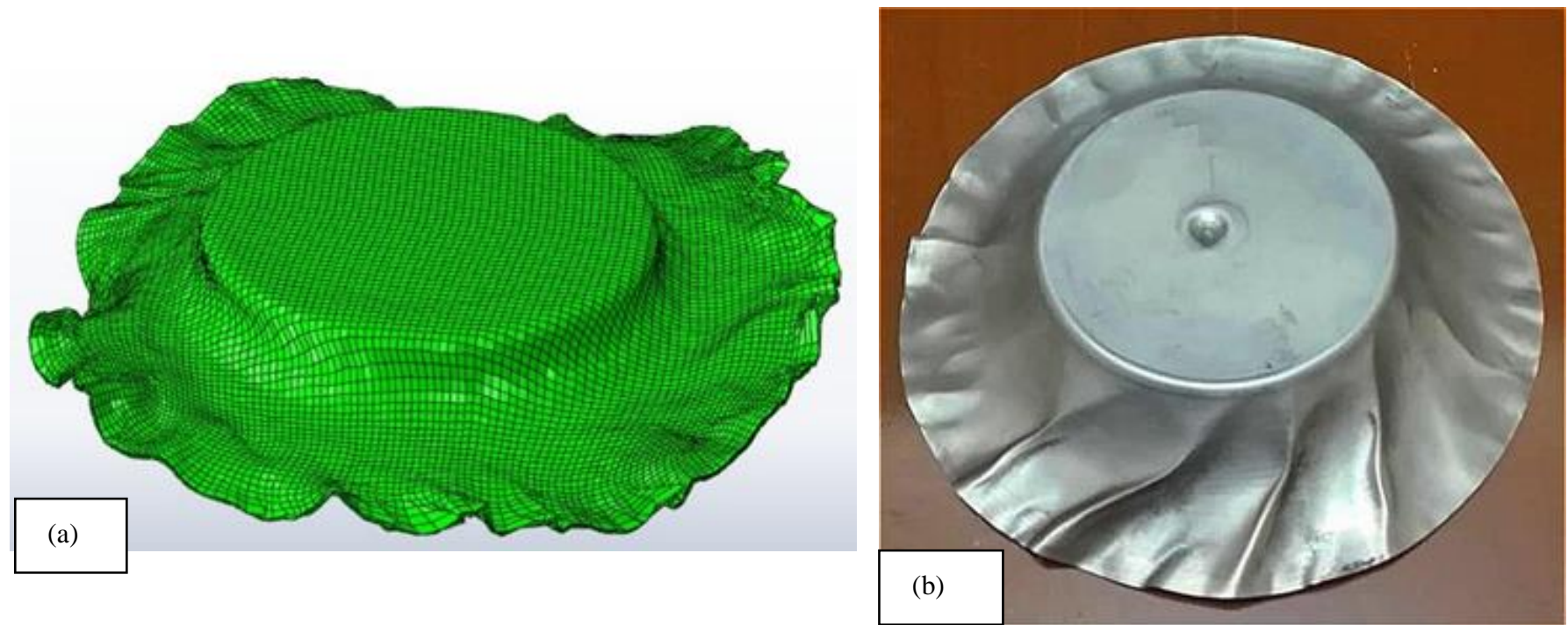

Figure 7. Configuration of sheet metal deformed at $\mathrm{f}=2 \mathrm{~mm} / \mathrm{s}$ and $\omega=60 \mathrm{rad} / \mathrm{s}$; a) FE simulation and b) experiment

\subsection{Effects of Process Parameters on the Stress- Strain Distribution in the Sheet Metal}

In FE simulations, the effects of spinning process parameters, including the roller feed rate (f) and the rotational speed of mandrel $(\omega)$ on the distribution of stress and equivalent strain in the sheet metal and their correlation with the wrinkling failure of the workpiece were investigated. For this purpose, three radial paths were defined on the blank, as represented in Fig. 8, and the average values of the stresses and equivalent strains along these paths were evaluated. 


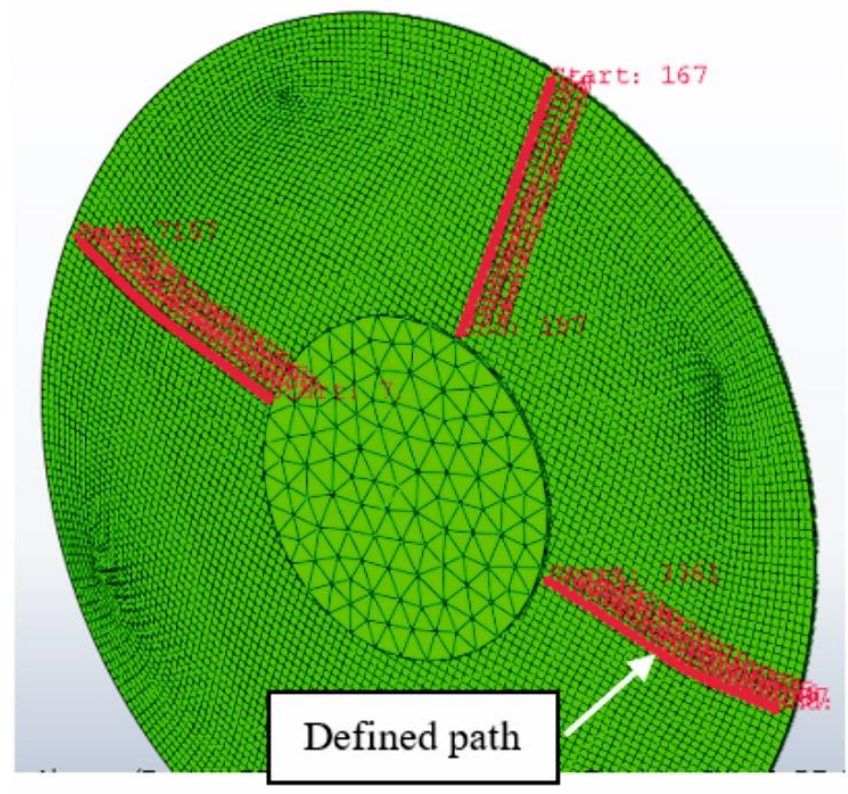

Figure 8. Definition of paths on the sheet plate

The distribution of von Mises stresses and equivalent plastic strain of workpiece as averages of distributions along the three paths represented in Fig. 8 for the

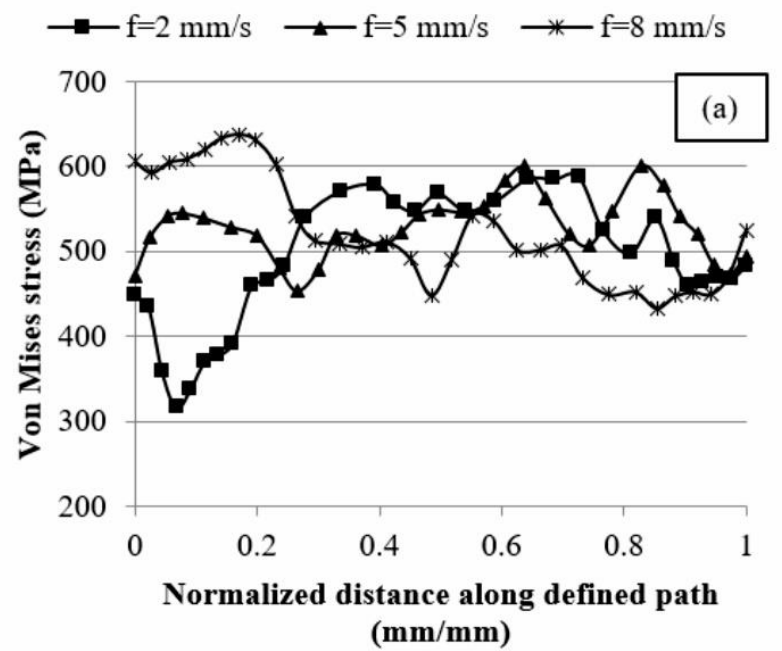

spinning process at a rotational speed of mandrel of 20 and $60 \mathrm{rad} / \mathrm{s}$ ( 190 and $570 \mathrm{rev} / \mathrm{min})$ are provided in Figs. 9 and 10, respectively. As represented in Fig. 9a, except for the initial or transient stage of plastic deformation at the beginning of the roller - sheet metal engagement, at a lower $\omega$-value of $20 \mathrm{rad} / \mathrm{s}$ the variation of von Mises stress with increasing roller feed rate is not significant. In other words, the energy required for plastic deformation of material does not change significantly by the increase in the roller feed rate at a rotational speed of mandrel of $20 \mathrm{rad} / \mathrm{s}$. This phenomenon is also represented in Fig. 11a for average von Mises stress distributions in specimens spun under different roller feed rates. However, as could be seen in Fig. 9b, the variation of roller feed rate has a significant effect on the distribution of equivalent plastic strain in the workpiece. As shown in this figure as well as Fig. 12a, by an increase in the roller feed rate at mandrel speed of $20 \mathrm{rad} / \mathrm{s}$, the permanent plastic stain of material decreases, and instead the outward flow and wrinkling of sheet metal occur that results in the failure of the spinning process. The configuration of deformed blank at $\omega=20 \mathrm{rad} / \mathrm{s}$ and various roller feed rates represented in Fig. 13 illustrates this explanation.

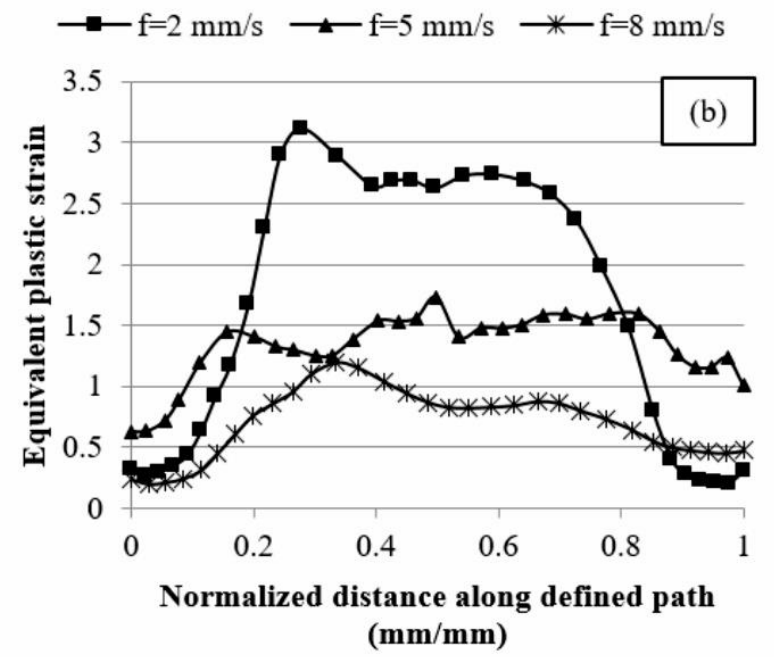

Figure 9. Von Mises stress and equivalent plastic strain distributions along the defined paths for parts spun at $\omega=20$ $\mathrm{rad} / \mathrm{s}$
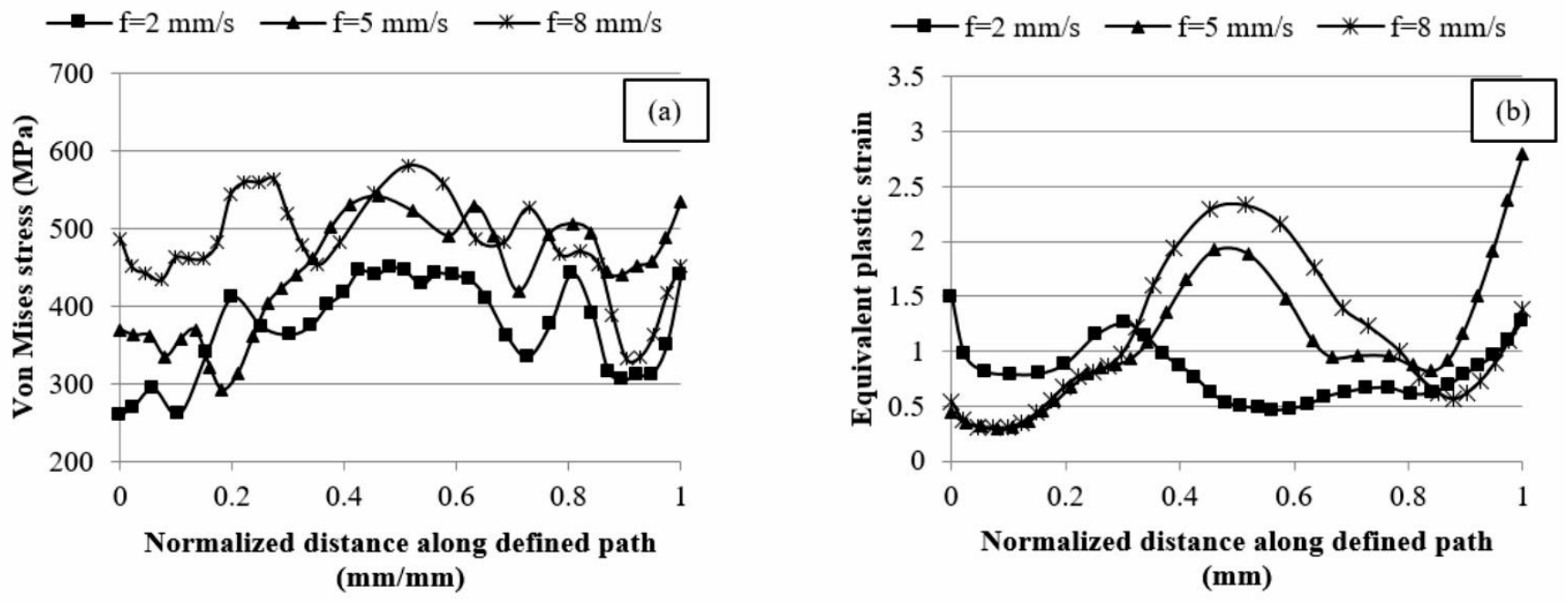

Figure 10. Von Mises stress and equivalent plastic strain distributions along the defined paths for parts spun at $\omega=60$ $\mathrm{rad} / \mathrm{s}$ 

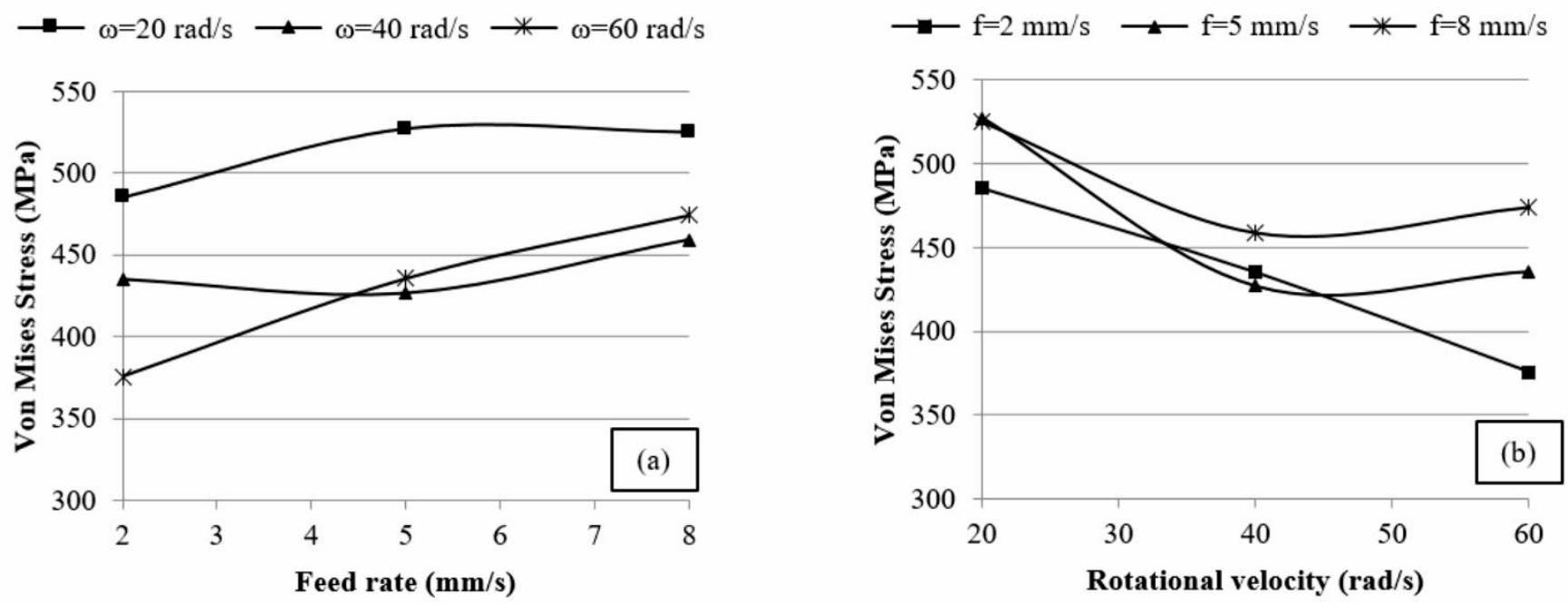

Figure 11. Average von Mises stress distributions along the defined paths for parts spun at different process parameters
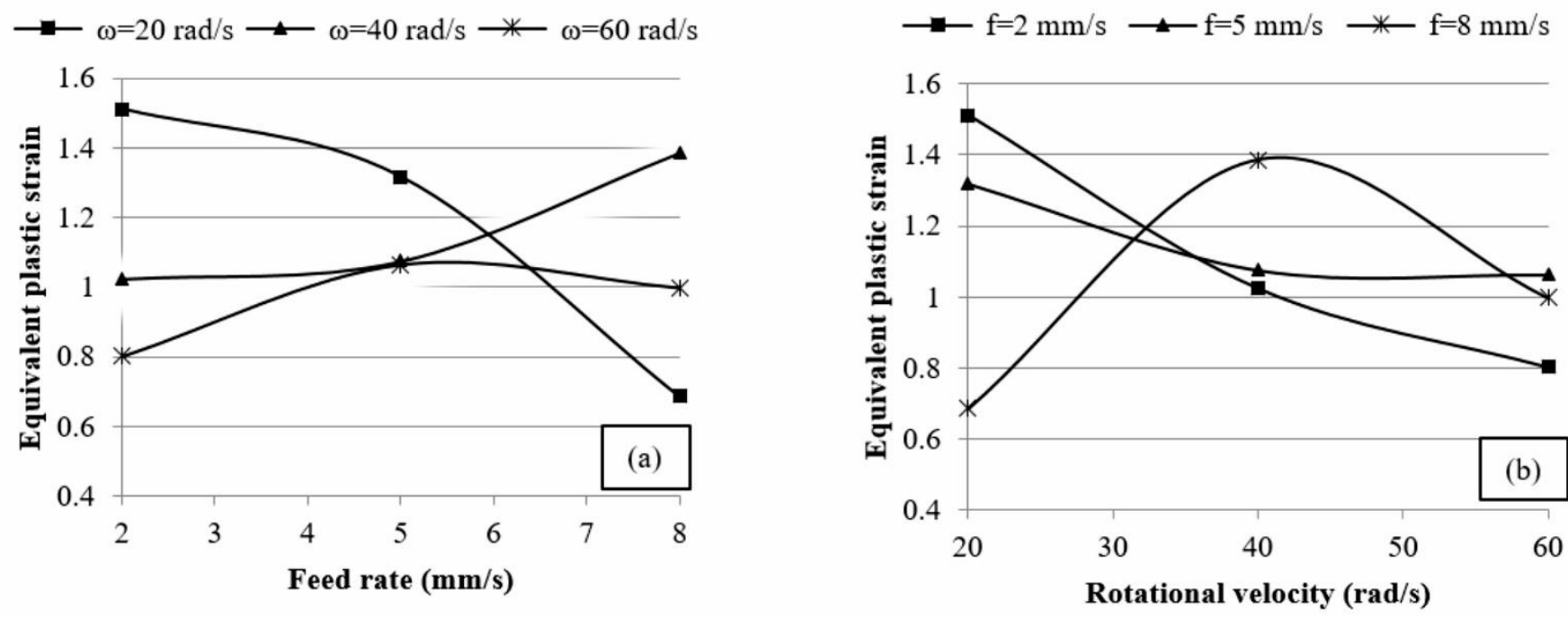

Figure 12. Average equivalent plastic strain distributions along the defined paths for parts spun at different process parameters

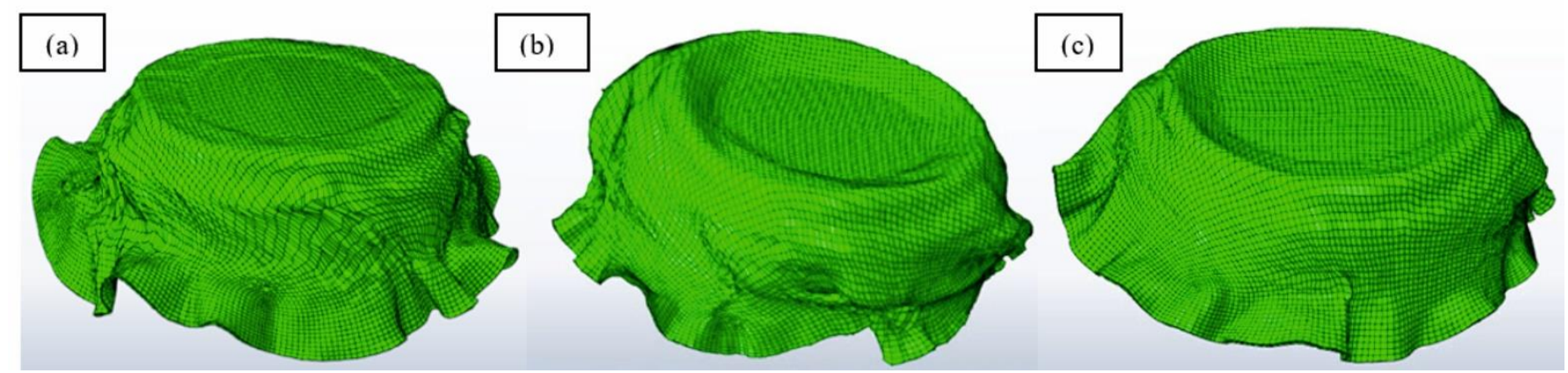

Figure 13. Configuration of sheet metal deformed under $\omega=20 \mathrm{rad} / \mathrm{s}$ at roller feed rate of a) 2, b) 5 and c) $8 \mathrm{~mm} / \mathrm{s}$

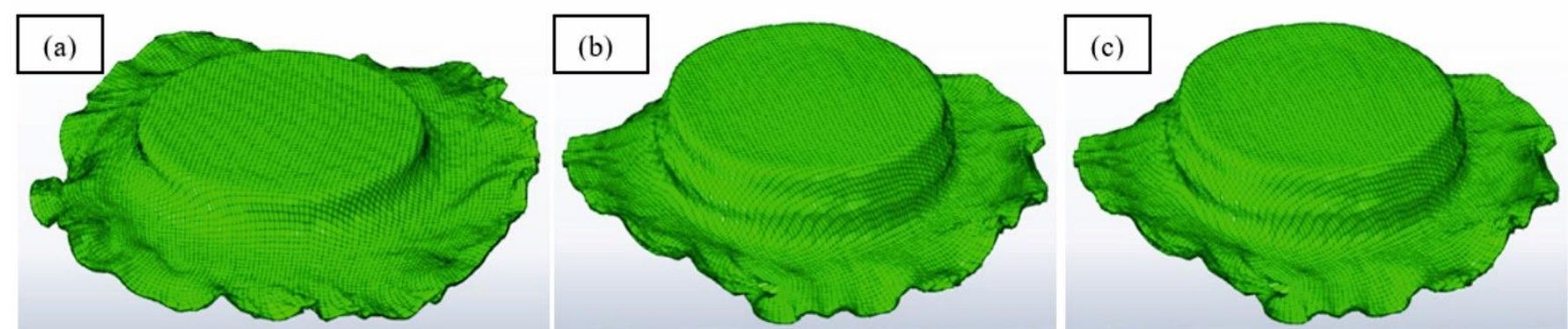

Figure 14. Configuration of sheet metal deformed under $\omega=60 \mathrm{rad} / \mathrm{s}$ at a roller feed rate of a) 2, b) 5 and c) $8 \mathrm{~mm} / \mathrm{s}$ 
Furthermore, as shown in Fig. 10a, unlike the spinning process at a lower mandrel velocity of $20 \mathrm{rad} / \mathrm{s}$, the von Mises stress or deformation energy at a high rotational speed of mandrel increases considerably with an increase in the roller feed rate. As represented in Fig. 14 , the process has come to a complete halt at the end of the first step of the mandrel due to the severe wrinkling of the circumferential area of the blank at the spinning parameter of $\mathrm{f}=2 \mathrm{~mm} / \mathrm{s}$ and $\omega=60 \mathrm{rad} / \mathrm{s}$. However, according to this figure, the simulation process was further progressed at higher roller feed rates of 5 and 8 $\mathrm{mm} / \mathrm{s}$ before breaking due to severe element distortion.

Furthermore, the increase in von Mises stress with an increase in roller feed rate at mandrel rotational speed of $60 \mathrm{rad} / \mathrm{s}$, as represented in Fig. 11a, is in correspondence with the increase of the density of dislocations in the material under plastic deformation due to increase strain rate (Callister and Rethwisch 2010). However, according to Fig. 11b, the required energy for deformation decreases continuously with an increase in the mandrel rotational speed for all levels of roller feed rate. This is because the roller velocity ratio, which is defined as the ratio of the feed rate of the roller to the rotational speed of the mandrel, decreases by the increase in the rotational speed of the mandrel. At the same time, according to Fig. 12a, the increase in the roller velocity ratio leads to increase in the equivalent plastic strain in the material except for the sheet metal spun under mandrel rotational speed of $20 \mathrm{rad} / \mathrm{s}$.

Furthermore, the distribution of von Mises stresses and equivalent plastic strain of workpiece as averages of

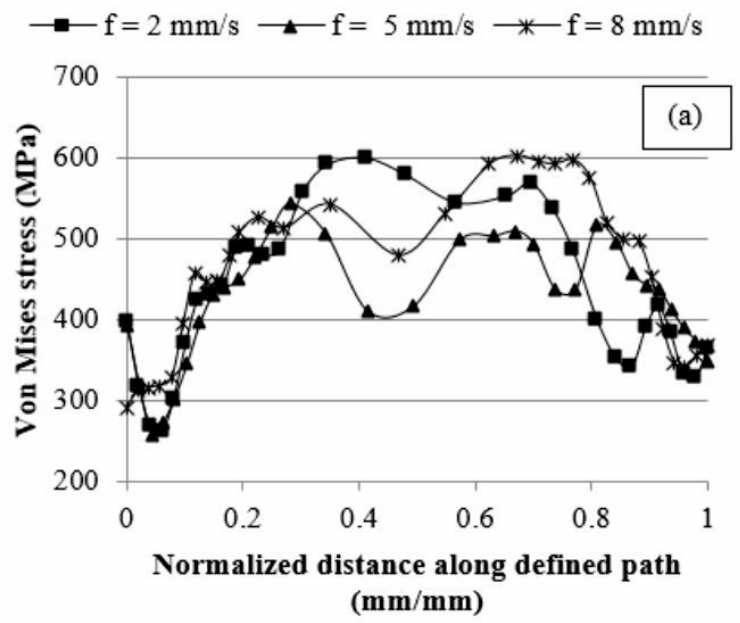

distributions along the defined paths on the blanks according to Fig. 8 at the spinning process with $\omega=40$ $\mathrm{rad} / \mathrm{s}(\sim 380 \mathrm{rev} / \mathrm{min})$ are shown in Fig. 15. According to this figure, the material experiences a similar distribution pattern of von Mises stress and equivalent plastic strain at $\omega=40 \mathrm{rad} / \mathrm{s}$ under different roller feed rates. However, the lowest deformation energy and the permanent plastic strain were observed at the roller feed rate $5 \mathrm{~mm} / \mathrm{s}$. According to Fig. 16, an increase in the roller feed rate from 2 to $5 \mathrm{~mm} / \mathrm{s}$ enhances the flow of material along the axis of the mandrel and leads to the reduction in the distortion of the workpiece. This in turn reduces the plastic strain, as represented in Fig. 15b, and the circumferential flow of material in the spinning process. However, as could be seen in Fig. 15, a further increase in the roller feed rate to $8 \mathrm{~mm} / \mathrm{s}$ results in a considerable rise in the deformation energy and permanent strain of the workpiece. This phenomenon is also represented in Figs. 11 and 12 for average von Mises stress and equivalent plastic strain distributions in specimens spun under $\omega$-parameter of $40 \mathrm{rad} / \mathrm{s}$. These findings show that wrinkling failure can be prevented and the uniformity of the deformation configuration of the sheet metal could be maintained provided that the roller velocity ratio is kept within the range of $0.5 \sim 1.3$ $\mathrm{mm} / \mathrm{rev}$ and the rotational speed of mandrel at about $380 \mathrm{rev} / \mathrm{min}$. It has been shown by Wang et al [7] that meeting this roller velocity ration range in the spinning process of cylindrical cups could prevent wrinkling failure.

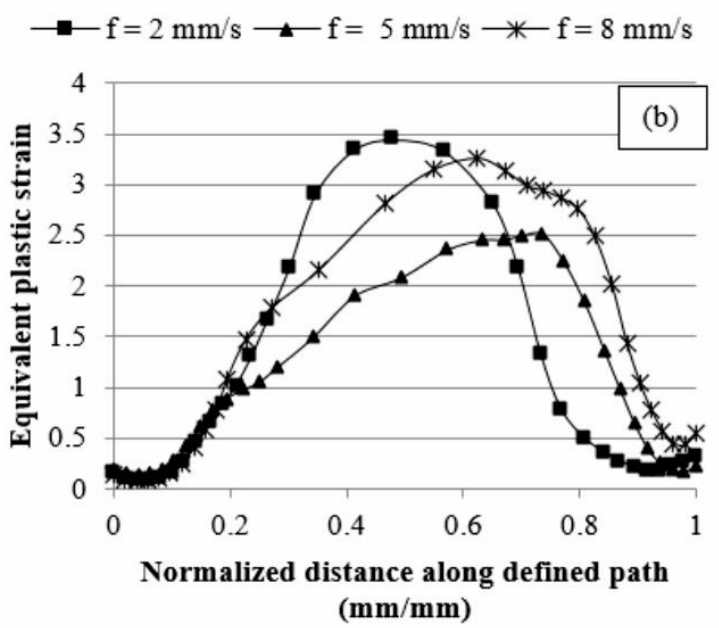

Figure 15. Von Mises stress and equivalent plastic strain distributions along the defined paths for parts spun at $\omega=40$ $\mathrm{rad} / \mathrm{s}$
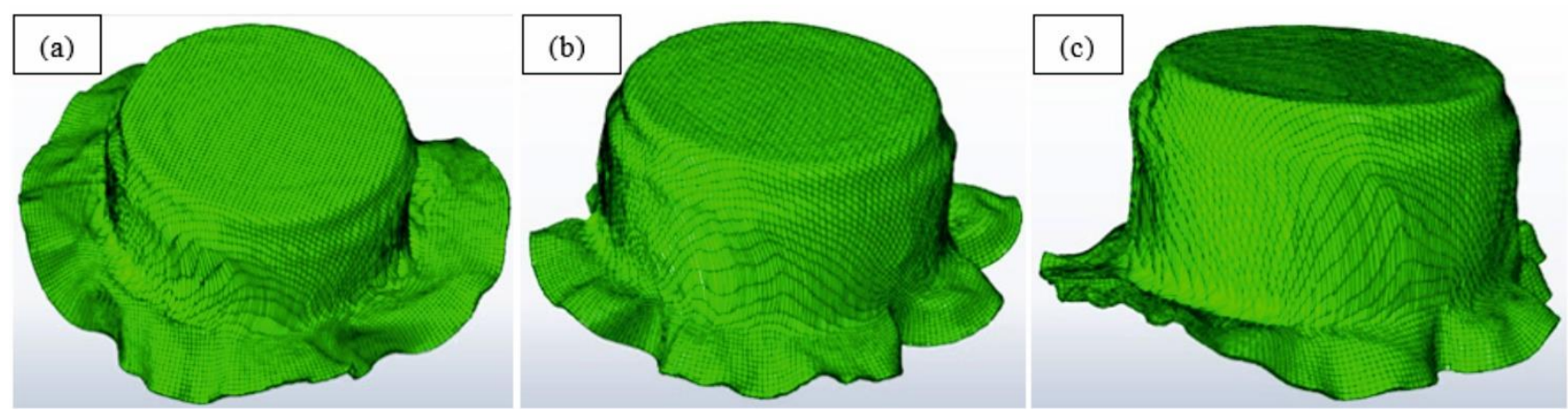

Figure 16. Configuration of sheet metal deformed under $\omega=40 \mathrm{rad} / \mathrm{s}$ at a roller feed rate of a) 2, b) 5 and c) $8 \mathrm{~mm} / \mathrm{s}$ 


\subsection{Effects of Process Parameters on the Wrinkling of the Sheet Metal}

Wrinkling is one of the main failure modes in the spinning process that significantly affects production efficiency and material formability (Wong et al. 2003). Therefore, understanding the mechanism of wrinkling and developing effective means for selecting process parameters to avoid this failure have been of objectives of this research. Wrinkling is caused due to the buckling of the unsupported blank of material under the deformation load of the roller (Wang et al. 2010). According to Kleiner et al. (2002), the dynamic aspect of the deformation process is dominant in this mode of failure. They reported that the diameter and thickness of blanks play major roles in determining the appropriate roller velocity ratio to prevent wrinkling failure. However, these static parameters are mainly decided based on the design considerations of the workpiece. Therefore, in this research, the roller feed rate and the rotational speed of the mandrel have been treated as the main parameters that determine the dynamic aspect of deformation and have a significant influence on the wrinkling failure of the blank.

According to Wang et al. (2010), tangential compressive stress is the cause of wrinkling in the spinning process of cylindrical cups. For this reason, the distribution of the tangential stress in the blank during the spinning process has been obtained by the FE model. The fluctuation of this stress from tensile to compressive has been acquired and evaluated for the study on the effects of roller feed rate and rotation speed of mandrel that enhance the possibility and severity of wrinkling in the spinning process. To acquire these stresses in the FE model, a circular path on the blank, as shown in Fig. 17, following the nodes in the adjacent of the perimeter has been defined.

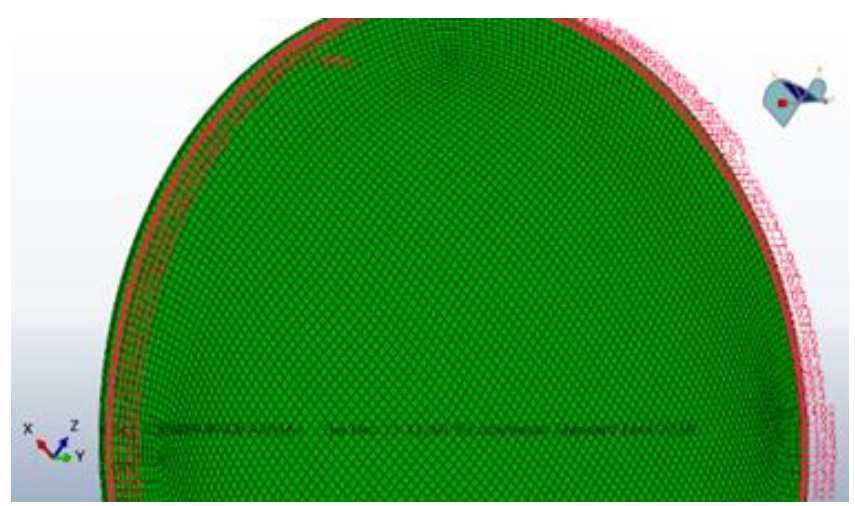

Figure 17. Definition of a circular path on the perimeter of the sheet plate

Typical distributions of the tangential stresses along the circular path shown in Fig. 17 for the two samples, one experiencing severe wrinkling and the other representing no wrinkling, are represented in Fig. 18. As shown in this figure, the tangential stress fluctuates more intensely between the tensile and compressive modes in spinning under the process parameters of $\mathrm{f}=2 \mathrm{~mm} / \mathrm{s}$ and $\omega=20 \mathrm{rad} / \mathrm{s}$ than that of at $\mathrm{f}=5 \mathrm{~mm} / \mathrm{s}$ and $\omega=40 \mathrm{rad} / \mathrm{s}$. The influence of these fluctuations on the wrinkling of the blank has previously been illustrated in Figs. 13a and 15b. The alteration of the tangential stress from tensile to the compressive mode and vice versa have been reported to be the source of intense vibration of the roller and onset of the wrinkling failure (Kleiner et al. 2002). To better evaluate the effects of roller feed rate and rotational speed of mandrel on the dynamics of spinning process and their effects on the wrinkling of the blank, the standard deviation of the tangential stresses at the last increment of the FE simulations were calculated and used as a measure of dispersion and fluctuation of tangential stress along the circumference of the spun workpiece. The following equation was used for these calculations.

$$
S_{\sigma}=\sqrt{\frac{\sum_{i=1}^{n}\left(\sigma_{i}-\sigma_{a v e}\right)}{n-1}}
$$

where $S_{\sigma}$ is the standard deviation of the tangential stress of the spun workpiece, $\sigma_{i}$ is the tangential stress of node 'n' along the circular path defined in Fig. 17 and $\sigma_{\text {ave }}$ is the average of tangential stresses of nodes along the circular path.

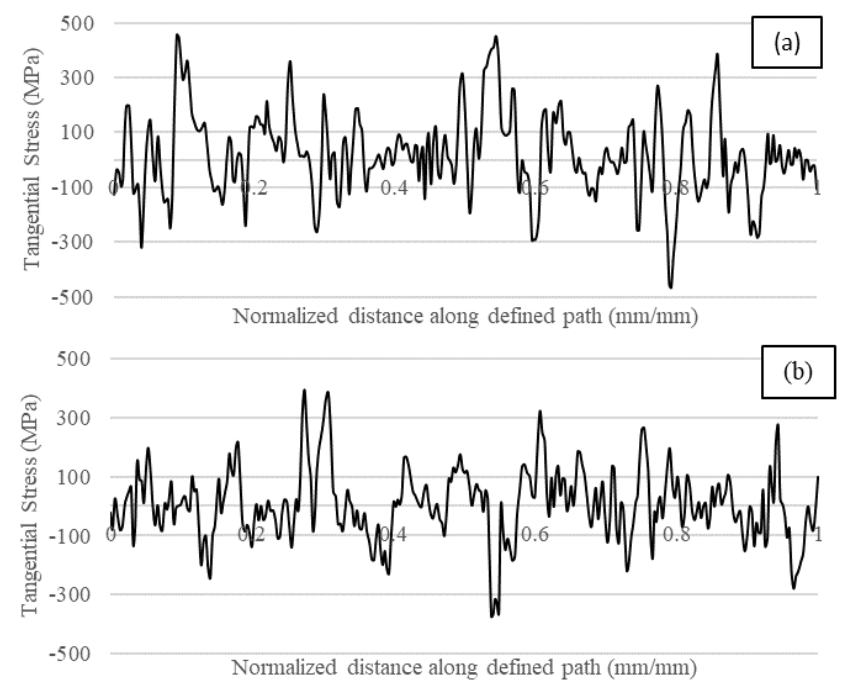

Figure 18. Distribution of tangential stress along the circular path around the circumference of blank; a) $f=2$ $\mathrm{mm} / \mathrm{s}, \omega=20 \mathrm{rad} / \mathrm{s}$ and b) $\mathrm{f}=5 \mathrm{~mm} / \mathrm{s}$ and $\omega=40 \mathrm{rad} / \mathrm{s}$

The results of the standard deviation of tangential stress distributions of spun specimens under various process parameters are represented in Fig. 19. As could be seen in Fig. 19a, regardless of the roller feed rate, the $\mathrm{S} \sigma$ had the minimum values at a rotational speed of 40 $\mathrm{rad} / \mathrm{s}$. However, at two other extremities of ' $\omega$ ' in these experiments, the fluctuations of tangential stress are significantly higher, that severe the vibrations of the roller and intensify the wrinkling failure. These conditions result in failure of the spinning process due to the wrinkling defect of the spun workpiece as shown in Figs. 13 and 14. Again in Fig.19b it is evident that the lowest fluctuations of the tangential stress and therefore the lowest possibility of the wrinkling failure occurs at about the rotational speed of mandrel of $40 \mathrm{rad} / \mathrm{s}$. However, not all the combinations of the ' $f$ ' and ' $\omega$ ' parameters result in the minimum $S \sigma$ values. 

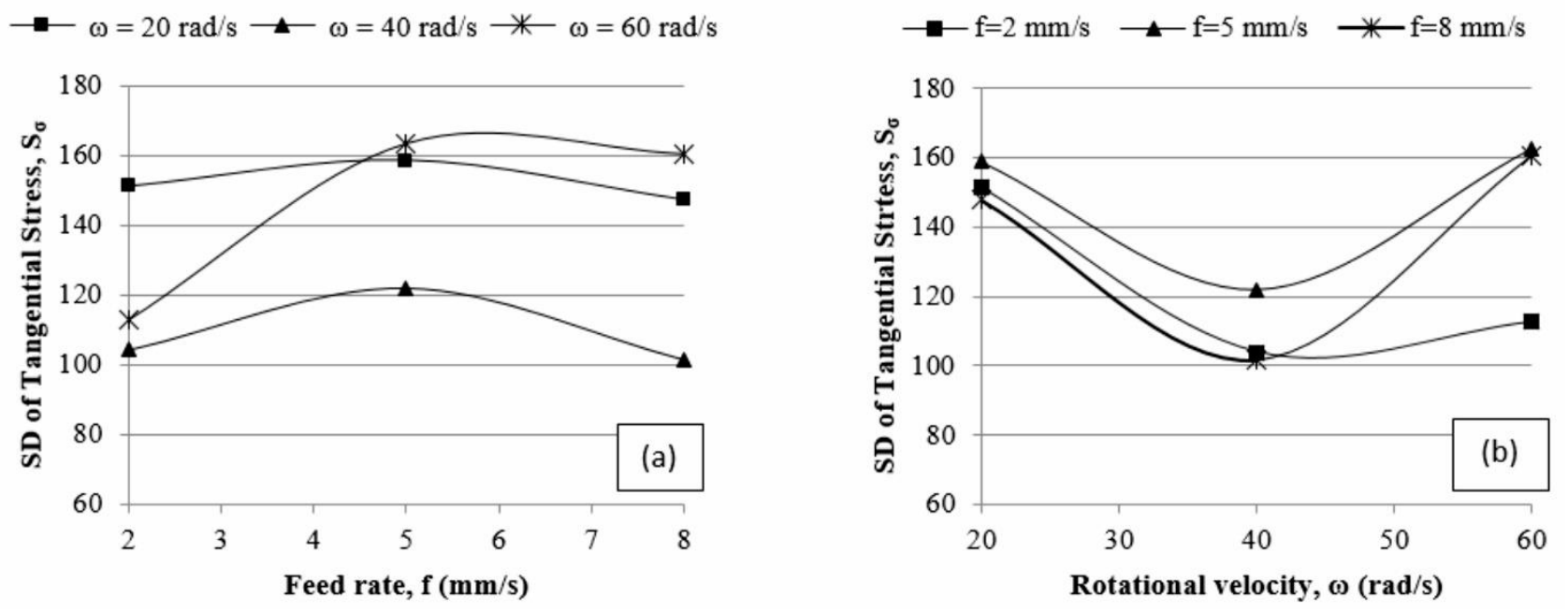

Figure 19. The standard deviation of tangential stress fluctuations along the circular path is defined on the perimeter of the spun workpiece under various process parameters.

\subsection{Effects of Process Parameters on the Thickness Variation of the Sheet Metal}

The distribution of the thickness of the spun parts as an average value of the thickness of sheet metal along the three paths defined as in Fig. 7, are represented in Fig. 20 for parts spun under different process parameters. As shown in this figure, the highest uniformity of the thickness of the workpiece at various roller feed rates has been observed for parts spun under rotational speed of mandrel of $40 \mathrm{rad} / \mathrm{s}$. This phenomenon is because the stress is distributed more uniformly at this $\omega$-value in comparison to that of under other rotational speeds. The lowest standard deviation of tangential stress under this spinning condition represented in Fig. 19 also corroborates these explanations. However, as shown in Fig. 19b, the spun parts at $\omega=40 \mathrm{rad} / \mathrm{s}$ experience more thickness reductions than that of under other rotations velocities of the mandrel. This could be because at this rotational velocity the energy of deformation was mainly consumed to deform the workpiece along the mandrel surface, while at a rotational speed of $20 \mathrm{rad} / \mathrm{s}$ the twisting and wrinkling of the sheet metal were dominant and under $\omega=60 \mathrm{rad} / \mathrm{s}$ the deformation process has been interrupted due to the excessive distortion of the material and the wrinkling failure. The configurations of spun parts in Figs. 13, 14, and 16 illustrate these explanations.

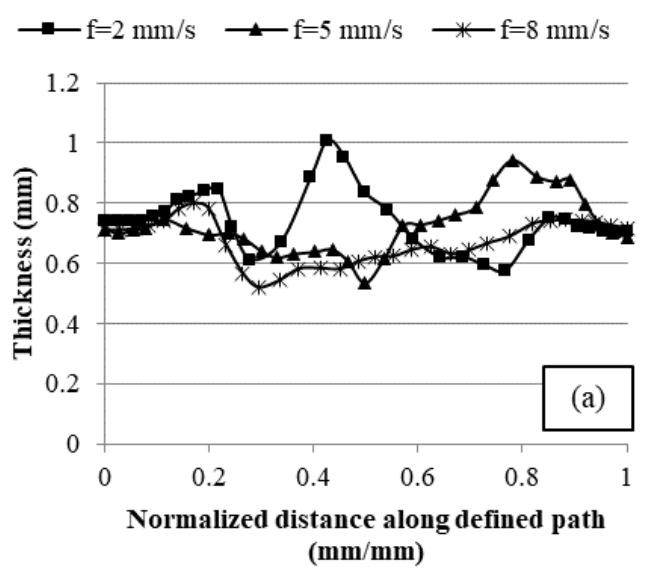

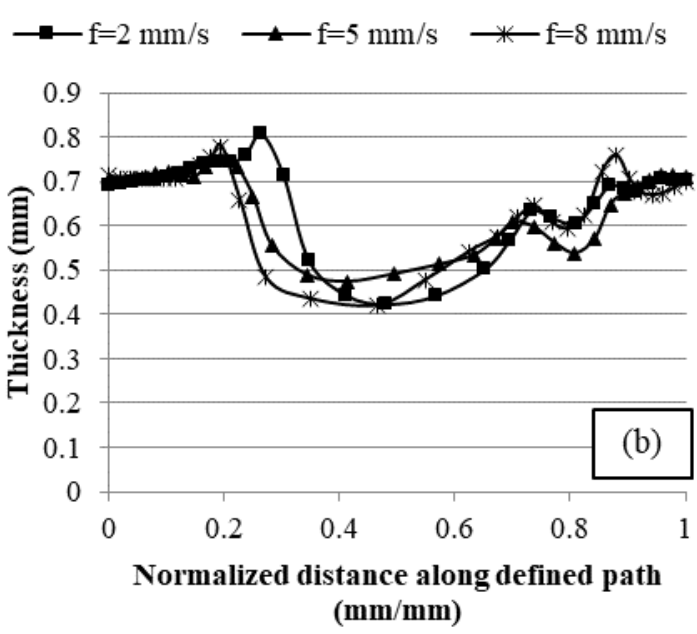

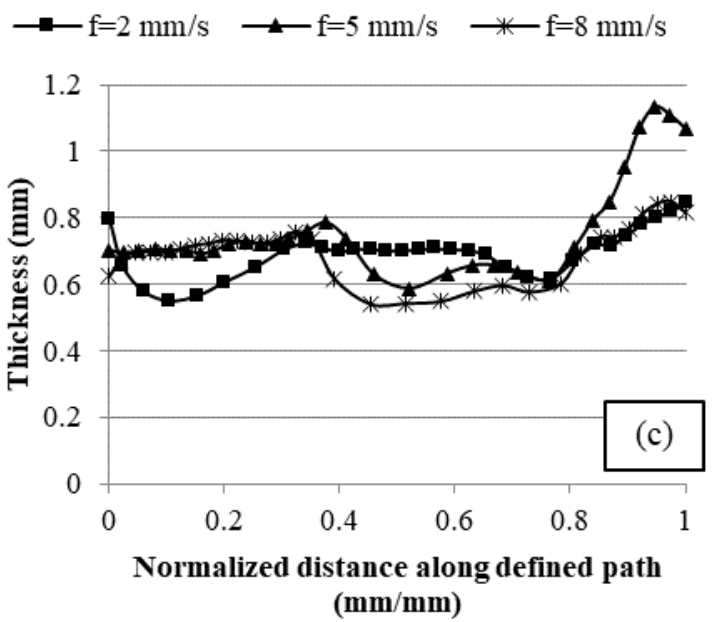

Figure 20. Average thickness distribution of spun part along the defined paths at; a) $\omega=20$, b) $\omega=40$ and c) $\omega=60$ $\mathrm{rad} / \mathrm{s}$

The deviation of the thickness of the workpiece from the initial thickness of the blank $\left(\mathrm{r}_{\mathrm{t}}\right)$ could be treated as one criterion to judge the quality of the spun parts. This deviation has been defined as the reduction of the blank thickness in the spinning process. The values of $r_{t}$ were 
calculated using Eq. 3. The results of these calculations are represented in Fig. 21.

$$
r_{t}=\frac{\left|t-t_{0}\right|}{t_{0}} \times 100
$$

where $t$ is the average thickness of the spun part measured along paths defined on the blank according to Fig. 7 and $t_{0}$ is the initial thickness of the blank.

As shown in Fig. 21, the thickness of the workpiece in the spinning process is mainly influenced by the rotational speed of the mandrel, while the effect of the

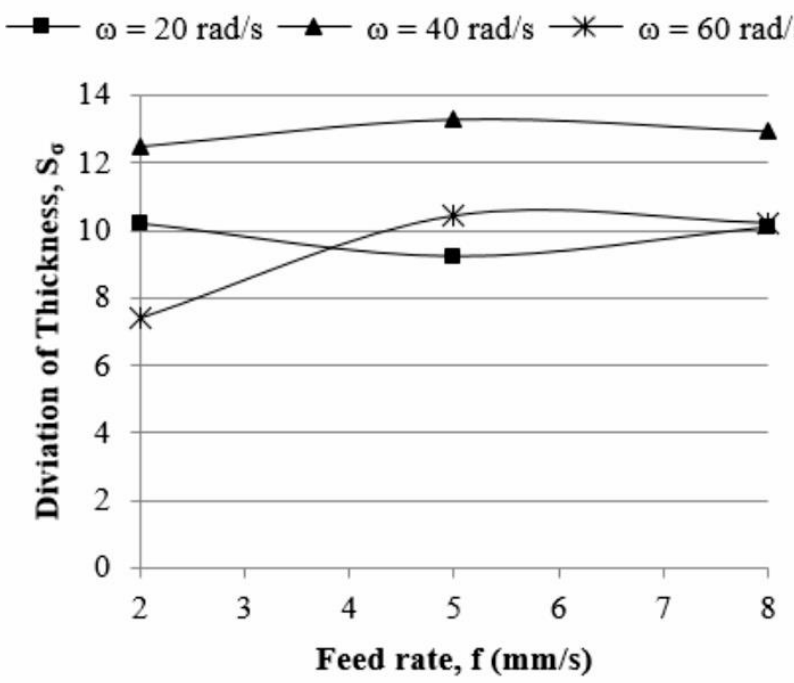

roller feed rate is less significant. According to Fig. 21a, the workpiece spun at $\omega=40 \mathrm{rad} / \mathrm{s}$ have experienced the highest deviation in the thickness than those spun under other conditions of rotations speed of mandrel. This phenomenon could be because the sheet metal in spinning under $\omega=40 \mathrm{rad} / \mathrm{s}$ undergoes deformation following the surface profile of the mandrel, while the blank under $\omega$-parameter of 20 and $60 \mathrm{rad} / \mathrm{s}$ experienced wrinkling and twisting during the deformation process. These explanations have been illustrated previously in Figs. 13, 14, and 16.

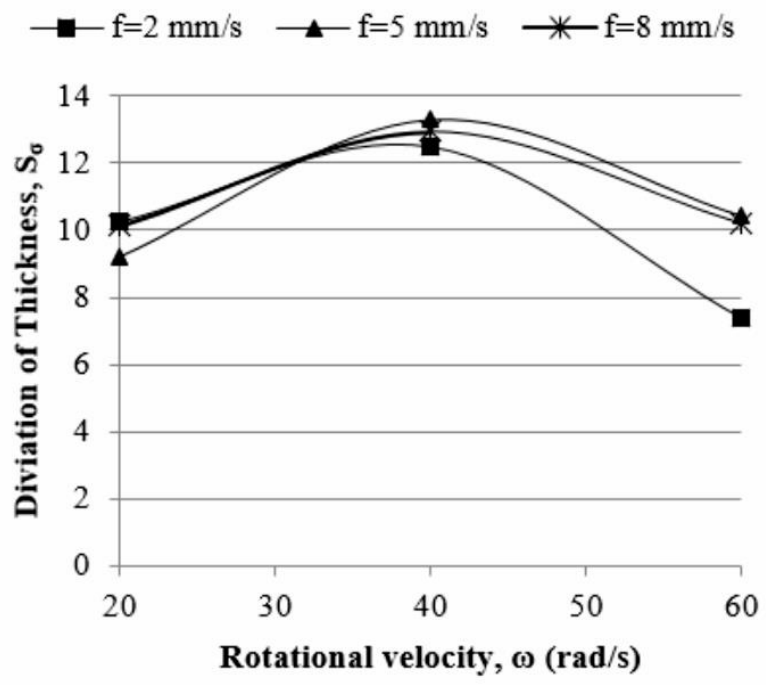

Figure 21. Deviation of the average thickness of spun parts from the initial thickness of blank under different spinning parameters

The final specimen formed by the spinning process at the process parameters of the roller feed rate of $5 \mathrm{~mm} / \mathrm{s}$ and rotational speed of mandrel of $40 \mathrm{rad} / \mathrm{s}$ is represented in Fig. 22. The holes in the forehead of this specimen are created using laser cutting.

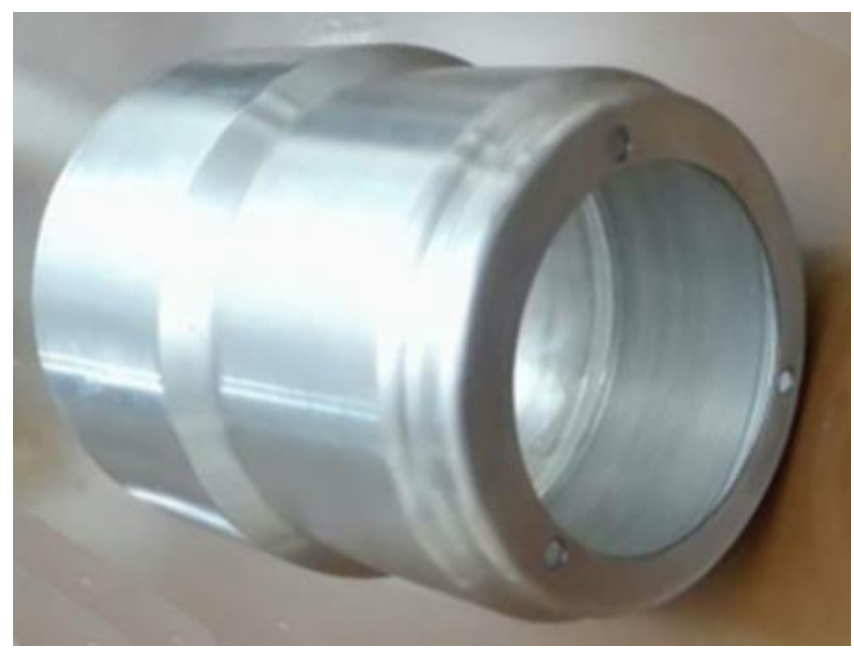

Figure 22. The final specimen of a stepped thin-walled cylindrical workpiece made by the spinning process under $\mathrm{f}=5 \mathrm{~mm} / \mathrm{s}$ and $\omega=40 \mathrm{rad} / \mathrm{s}$

\section{CONCLUSION}

In this research, the formation of a stepped thinwalled cylinder of AISI 316 stainless steel by the spinning process was studied. A finite element model was developed to investigate the effects of process parameters, including the roller feed rate and rotational speed of mandrel, in distributions of stress and strain, wrinkling, and thickness variations of the spun parts. Experiments have been conducted to verify the accuracy of the developed FE model and to prototype parts based on the optimum process parameters obtained by simulations. The followings are the leading conclusions of this study:

- At a lower rotational speed of mandrel, the energy required for plastic deformation of material did not change significantly by the increase in the roller feed rate, while the permanent plastic strain of the material decreased and instead the outward flow and wrinkling of sheet metal occurred that resulted in the decrease of equivalent plastic strain in the workpiece. At a high rotational speed of the mandrel, the deformation energy, and plastic strain increased considerably with an increase in the roller feed rate.

- At a lower relative velocity of the roller (roller feed rate to the rotational speed of mandrel), while the rotational speed of the mandrel is high, the spinning process came to a complete halt at the initial stage of the deformation process due to the severe wrinkling of the circumference of the blank. However, the process continued at higher relative velocities of the roller caused by an increase in the roller feed rate.

- The material experienced a similar distribution pattern of von Mises stress and equivalent plastic strain at a rotational velocity of $40 \mathrm{rad} / \mathrm{s}$ under different roller feed rates. However, the increase in 
the relative velocity of the roller by increase in the roller feed rate enhanced the flow of material along the axis of the mandrel and led to the reduction in distortion and wrinkling of the workpiece.

- The tangential stress of the parts fluctuated more intensely between the tensile and compressive modes in spinning processes at which the spun parts experienced wrinkling and twisting failures. Regardless of the roller feed rate, these fluctuations had the minimum values at a rotational speed of 40 $\mathrm{rad} / \mathrm{s}$ in comparison to other extremities of this parameter in the experiments. However, not all the combinations of the roller feed rate and rotational velocity of the mandrel resulted in the minimum standard deviations of tangential stresses of the spun parts.

- The thickness of the workpiece in the spinning process was mainly influenced by the rotational speed of the mandrel, while the effect of the roller feed rate was less significant. The highest uniformity of the thickness of the workpiece has been observed for parts spun under rotational speed of mandrel of $40 \mathrm{rad} / \mathrm{s}$ because the stresses were distributed more uniformly under this process parameter. However, the parts experienced more thickness reductions under this condition since the energy of deformation was mainly consumed to deform the workpiece along the mandrel surface, while under other extremities of this parameter the twisting and wrinkling of the sheet metal were dominant.

\section{Authors Contributions}

Mirsadegh Seyedzavvar wrote the manuscript getting contributions from all authors; Samet Akar and Mirsadegh Seyedzavvar have conceived the idea, designed the experiments, and analyzed the results and data; Mirali Seyedzavvar conducted the finite element simulations; Mirali Seyedzavvar and Hossein Abbasi conducted the experiments and collected the data.

\section{Conflict of Interest Statement}

The authors of this work certify that they have NO affiliations with or involvement in any organization or entity with any financial or non-financial interest in the subject matter or materials discussed in this manuscript. The corresponding author is prepared to collect documentation of compliance with ethical standards and send it if requested during peer review or after publication. The Editors reserve the right to reject this manuscript if it does not comply with these certifications

\section{REFERENCES}

Ahmed K I, Gadala M S, El-Sebaie M G (2015). Deep spinning of sheet metals. International Journal of Machine Tools and Manufacture, 97, 72-85.

AMS 5528. Stainless Steel Sheet, United Performance Metals,

https://www.upmet.com/products/stainlesssteel/17-7-ph
Becker C, Erman Tekkaya A (2015) Wall thickness distribution during a combined tube spinning and bending process. Key Engineering Materials, 651653:1614-1619.

Bi D, Yang G, Chu L, Zhang J, Wang Z (2012). Numerical simulation on spinning forming process of automotive wheel rim. Materials Science Forum, 704705:1458-1464.

Callister W D, Rethwisch D G (2010). Materials science and engineering: An introduction, $8^{\text {th }}$ edition. John Wiley \& Sons, Inc.

Cheong W C, Kam H K, Wang C C, Lim Y P (2013). Study of cold rotary forming by using rigid-plastic finite element method. Advanced Materials Research, 626, 662-666.

Davidson M J, Balasubramanian K, Tagore G R N (2008). An experimental study on the quality of flow-formed AA6061 tubes. Journal of materials processing technology, 203(1-3), 321-325.

Dynamic analysis procedures (DAP): overview, Abaqus analysis user's guide, Dassault Systemes, https://bit.ly/2IMZ80R

Feifei S, He Y, Heng L, Mei Z, Guangjun L (2013). Springback prediction of thick-walled high-strength titanium tube bending. Chinese Journal of Aeronautics, 26: 1336-1345.

Huang C C, Hung J C, Hung C, Lin C R (2011). Finite element analysis on neck-spinning process of tube at elevated temperature. The International Journal of Advanced Manufacturing Technology 56:1039-1048.

Jahazi M, EbrahimiG (2000). The influence of flowforming parameters and microstructure on the quality of a D6ac steel. Journal of materials processing technology, 103, 362-366.

Jia Z, Han Z R, Xu Q, Peng W F, Kong Q M (2015). Effects of processing parameters on the surface quality of square section die-less spinning. The International Journal of Advanced Manufacturing Technology, 80(9), 1689-1700.

Kalpakjian S, Schmid S R (2006). Chp 16: Sheet metal forming process and equipment, Manufacturing engineering and technology. $6^{\text {th }}$ edition, Pearson Publication.

Kleiner M, Göbel R, Kantz H, Klimmek C H, Homberg W (2002). Combined methods for the prediction of dynamic instabilities in sheet metal spinning. CIRP Annals 51:209-214.

Li Y, Wang J, Lu G D, Pan G J (2014). A numerical study of the effects of roller paths on dimensional precision in die-less spinning of sheet metal. J Zhej Uni-SCI A (App Phy Eng) 15(6):432-446.

Marghmaleki I S, Beni Y T, Noghrehabadi A R, Sadat Kazemi A, Abadyan M (2011). Finite element simulation of thermomechanical spinning process. Proc Eng 10:3769-3774.

Molladavoudi H R, Djavanroodi F (2011). Experimental study of thickness reduction effects on mechanical properties and spinning accuracy of aluminum 70750 , during flow forming. The International Journal of Advanced Manufacturing Technology 52:949-957.

Mori K, Nonaka T (2005). Simplified three-dimensional finite element simulation of shear spinning process 
based on axisymmetric modeling. Journal of manufacturing processes, 7(1),51-56.

Moria K, Ishigurob M, Isomura Y (2009). Hot shear spinning of cast aluminum alloy parts. Journal of Materials Processing Technology, 209:3621-3627.

Murata M, Kuboki T, Murai T (2005). Compression spinning of circular magnesium tube using heated roller tool. Journal of materials processing technology, 162, 540-545.

Parsa M H, Pazooki A M A, Nili Ahmadabadi M (2009). Flow-forming and flow formability simulation. The International Journal of Advanced Manufacturing Technology, 42(5-6), 463-473.

Russo I M, Cleaver C J, Allwood J M, Loukaides E J (2020). The influence of part asymmetry on the achievable forming height in multi-pass spinning. Journal of Materials Processing Technology, 275, 116350.

Sangkharat T, Dechjarern S (2017). Spinning process design using finite element analysis and Taguchi method. Procedia Engineering, 207, 1713-1718.

Sreenivasan, P R, Rayb S K (2001). Mechanical Testing at High Strain Rates. Enc. Mater.: Sci. Tech. (2nd Ed.) 5269-5271.

Sugita Y, Arai H (2015). Formability in synchronous multipass spinning using simple pass set. Journal of Materials Processing Technology, 217, 336-344.

Wang L, Long H, Ashley D, Roberts M, White P (2010). Effects of the roller feed ratio on wrinkling failure in conventional spinning of a cylindrical cup.
Proceedings of the Institution of Mechanical Engineers, Part B: Journal of Engineering Manufacture, 225(11), 1991-2006

Wang X X, Zhan M, Fu M W, Guo J, Xu R Q, Lei X P (2017). A unique spinning method for grain refinement: repetitive shear spinning. Procedia Engineering, 207,1725-1730.

Wong C C, Danno A, Tong K K, Yong M S (2008). Cold rotary forming of thin-wall component from flat-disc blank. Journal of materials processing technology, 208:53-62.

Wong C C, Dean T A, Lin J (2003). A review of spinning, shear forming and flow forming processes. International Journal of Machine Tools and Manufacture, 43(14), 1419-1435.

Xia Q, Cheng X, Long H, Ruan F (2012). Finite element analysis and experimental investigation on deformation mechanism of non-axisymmetric tube spinning. The International Journal of Advanced Manufacturing Technology, 59(1-4), 263-272.

Zhan M, Guo J, Fu M W, Li R, Gao P F, Long H, Ma F (2018). Formation mechanism and control of flaring in forward tube spinning. The International Journal of Advanced Manufacturing Technology, 94, 59-72. 